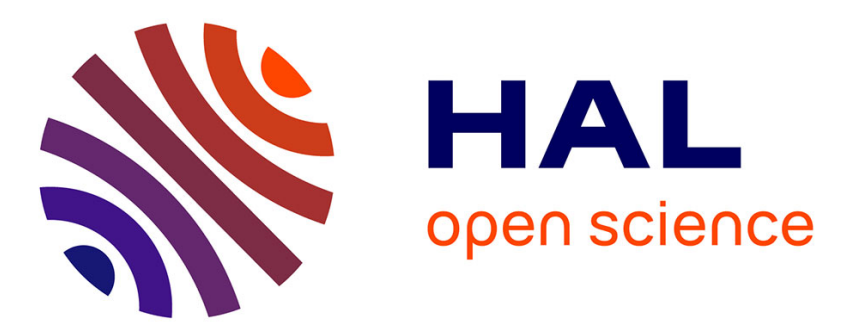

\title{
Affordable Estimation of Solvation Contributions to the Adsorption Energies of Oxygenates on Metal Nanoparticles
}

Federico Calle-Vallejo, Rodrigo F. de Morais, Francesc Illas, David Loffreda, Philippe Sautet

\section{- To cite this version:}

Federico Calle-Vallejo, Rodrigo F. de Morais, Francesc Illas, David Loffreda, Philippe Sautet. Affordable Estimation of Solvation Contributions to the Adsorption Energies of Oxygenates on Metal Nanoparticles. Journal of Physical Chemistry C, 2019, 123 (9), pp.5578-5582. 10.1021/acs.jpcc.9b01211 . hal-02119986

\section{HAL Id: hal-02119986 https://hal.science/hal-02119986}

Submitted on 8 Nov 2021

HAL is a multi-disciplinary open access archive for the deposit and dissemination of scientific research documents, whether they are published or not. The documents may come from teaching and research institutions in France or abroad, or from public or private research centers.
L'archive ouverte pluridisciplinaire HAL, est destinée au dépôt et à la diffusion de documents scientifiques de niveau recherche, publiés ou non, émanant des établissements d'enseignement et de recherche français ou étrangers, des laboratoires publics ou privés. 


\section{Affordable Estimation of Solvation}

\section{Contributions to the Adsorption Energies of}

\section{Oxygenates at Metal Nanoparticles}

Federico Calle-Vallejo ${ }^{1, *}$, Rodrigo F. de Morais ${ }^{2}$, Francesc Illas, ${ }^{1}$ David Loffreda ${ }^{2}$, and Philippe Sautet ${ }^{3,4, *}$

${ }^{1}$ Departament de Ciència de Materials i Química Física \& Institut de Química Teòrica i Computacional (IQTCUB), Universitat de Barcelona, Martí i Franqués 1, 08028 Barcelona, Spain.

${ }^{2}$ Univ Lyon, ENS de Lyon, CNRS, Université Lyon 1, Laboratoire de Chimie UMR 5182, F69342, Lyon, France.

${ }^{3}$ Department of Chemical and Biomolecular Engineering, University of California, Los Angeles, Los Angeles, California 90095, United States.

${ }^{4}$ Department of Chemistry and Biochemistry, University of California, Los Angeles, Los Angeles, California 90095, United States.

*Address correspondence to: f.calle.vallejo@ub.edu, sautet@ucla.edu 


\section{ABSTRACT}

Electrocatalysts are mainly characterized by their intrinsic adsorption properties. However, the observed electrocatalytic activity ultimately results from the interplay between such properties and various additional interactions within the electrified solid-liquid interface. One of such phenomena is solvation, which can substantially affect the stability of adsorbates. The incorporation of solvation in computational electrocatalysis models can be fully implicit (inaccurate for $\mathrm{H}$-bonded adsorbates), fully explicit (challenging computation of free energies), or embedded. Here we show that without any need for explicit or implicit media, a micro-solvation approach with just 3 water molecules captures the contribution of coadsorbed water to the adsorption energies of $* \mathrm{OH}$ and $* \mathrm{OOH}$ (two important adsorbates for oxygen reduction) on platinum nanoparticles of various sizes. The approach enables an accurate yet inexpensive explicit modeling of solvent-adsorbate interactions in nanoparticles, and the calculation of solvation corrections, estimated as $-0.59 \pm 0.14 \mathrm{eV}$ and $-0.47 \pm 0.13 \mathrm{eV}$ for *OH and $* \mathrm{OOH}$ adsorption on Pt.

\section{TOC GRAPHICS}
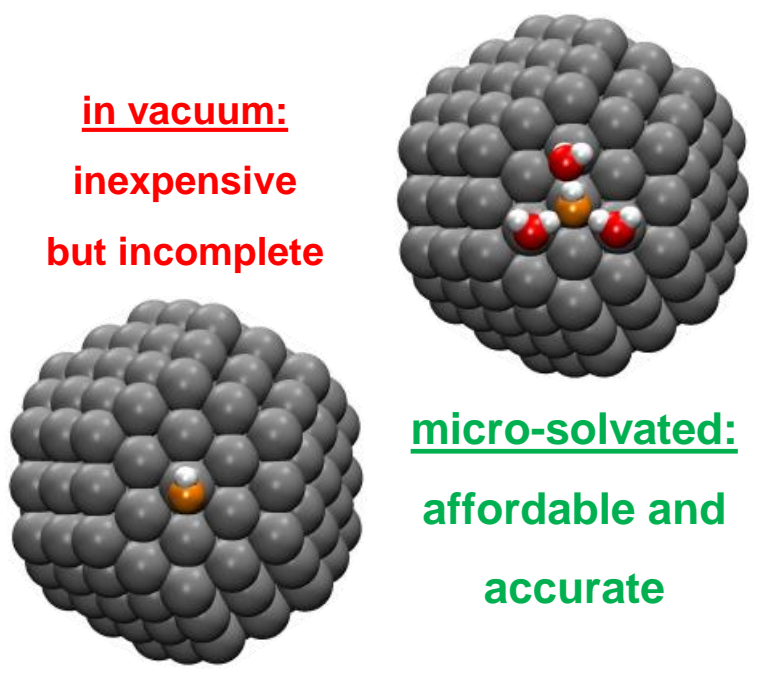

\section{in solution:} complete but

micro-solvated: affordable and accurate expensive

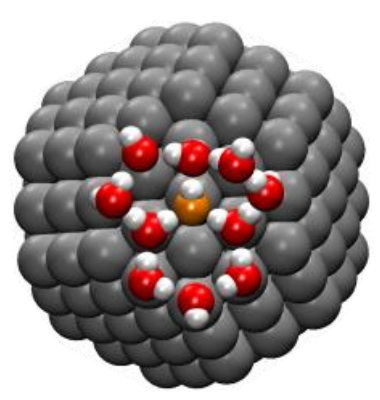


The efficiency of renewable-energy-based technologies such as fuel cells and electrolyzers is adversely affected by the low performance of the involved electrocatalytic processes. The much-needed improvement is difficult, as the electrocatalytic activity of materials results from a combination of several factors: first, the electronic and geometric structures of solids, which display beneficial or deleterious interactions with the reactants, intermediates and products of catalytic reactions. ${ }^{1}$ Second, substrate-adsorbate interactions are modified by $\mathrm{pH}$, electrolyte, solvent, and electric-field effects. ${ }^{2}$

Thermodynamically, substrate-adsorbate interactions are captured by adsorption energies $\left(\Delta G_{A D S}\right)$, which are strongly correlated with the geometric and electronic structures of materials. ${ }^{1,3-6}$ In addition, one can assess the influence of electric fields ${ }^{7}$ and $\mathrm{pH}^{8}$ on $\Delta G_{A D S}$. Solvent effects may be accounted for using implicit models, ${ }^{6}, 9-10$ though it is generally desirable to include them explicitly, especially when strong solvent-adsorbate interactions such as H-bonds are present. ${ }^{11}$ Embedded methods exist with explicit solvent molecules in the first solvation shell and an implicit medium beyond, but the results need careful benchmark. ${ }^{12-}$ ${ }^{14}$ All those models capitalize on the conclusions and advances on the solvation of chemical species, mostly ions, in solution, which is a well-established field of research. ${ }^{12,15-17}$

For water, the most common solvent, different adsorbed frameworks depending on the surface morphology are observed. ${ }^{18-22}$ Such "water bilayers" modify $\Delta G_{A D S}$ of reaction intermediates: several studies have shown the importance of $* \mathrm{OH}$ and $* \mathrm{OOH}$ solvation by water for computational models of the oxygen reduction reaction (ORR) to be quantitatively comparable to experiments. ${ }^{14,19,23-26}$ Explicit ice-like hexagonal water layers over pristine close-packed surfaces of transition metals are typically used (Figure 1b). ${ }^{9}, 18,20$ Such explicit approach is computationally affordable depending on the size of the surface unit cells, but its use on realistic nanoparticles is challenging: for instance, Pt nanoparticles with diameters of $\sim 3 \mathrm{~nm}$, which display maximum mass activity for the ORR, ${ }^{27}$ possess hundreds of surface 
atoms. Modelling a $\sim 1.7 \mathrm{~nm}$ nanoparticle immersed in explicit water by ab-initio molecular dynamics (AIMD) already requires including $\sim 700 \mathrm{H}_{2} \mathrm{O}$ molecules. ${ }^{11}$ Besides, finite-size effects $^{3,}$ 28-29 frequently prevent straightforward extrapolation of conclusions drawn from extended surfaces to nanoparticles.

Thus, the question is whether computationally inexpensive explicit solvation schemes can be devised for nanoparticles. Here we offer an affordable micro-solvation approach to account for water solvation tested for $* \mathrm{OH}$ and $* \mathrm{OOH}$ on Pt nanoparticles of various sizes. The reactions used to calculate the adsorption energies of $* \mathrm{OH}$ and $* \mathrm{OOH}\left(\Delta G_{O H}\right.$ and $\left.\Delta G_{O O H}\right)$ are:

$$
\begin{aligned}
& *+(n+1) \mathrm{H}_{2} \mathrm{O} \rightarrow * \mathrm{OH}+n \mathrm{H}_{2} \mathrm{O}+\mathrm{H}^{+}+e^{-} \\
& *+(n+2) \mathrm{H}_{2} \mathrm{O} \rightarrow * \mathrm{OOH}+n \mathrm{H}_{2} \mathrm{O}+3\left(\mathrm{H}^{+}+e^{-}\right)
\end{aligned}
$$

Where * denotes a free adsorption site, and proton-electron pairs are described using the computational hydrogen electrode, so $\frac{1}{2} \mu\left(H_{2}\right)=\mu\left(H^{+}+e^{-}\right) \cdot{ }^{23}$ The way in which $\mathrm{H}_{2} \mathrm{O}$ is accounted for in these equations affects substantially the actual values of the adsorption energies. Consider the following cases on $\mathrm{Pt}(111)$ : a) $\mathrm{H}_{2} \mathrm{O}$ from gas-phase calculations, ("in vacuum”, $n=0)$. b) Periodic adsorbed $\mathrm{H}_{2} \mathrm{O}$ bilayers $(n \rightarrow \infty$, depending on the size of the slab. $n=5$ in Figure $1 \mathrm{~b}$ for a $3 \times 3$ slab). c) Adsorbed $\mathrm{H}_{2} \mathrm{O}$ molecules close to the adsorbates and H-bound to them ("micro-solvation", $n=2$ ). These configurations are displayed in Figure 1 for $* \mathrm{OH}$ and $* \mathrm{OOH}$. Figure $1 \mathrm{~b}$ corresponds to the well-known "half-dissociated" water layers ${ }^{30}$ in which each adsorbate is surrounded by three water molecules. Note that previous reports showed that $1-2$ water molecules are insufficient to fully solvate $*$ OH. ${ }^{14}$ 
a) vacuum (vac)

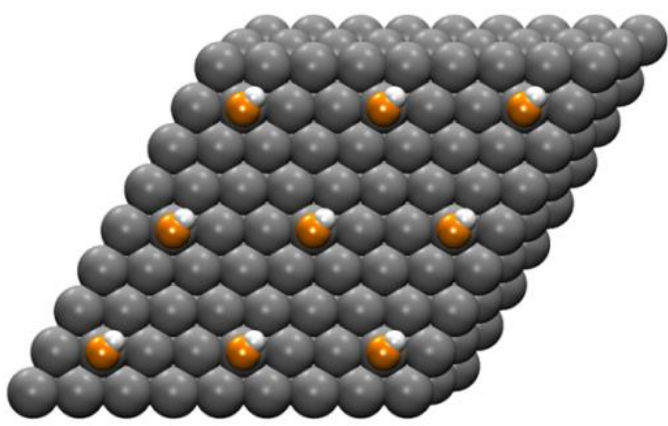

$\Delta G_{O H}^{v a c}=1.17 \mathrm{eV}$

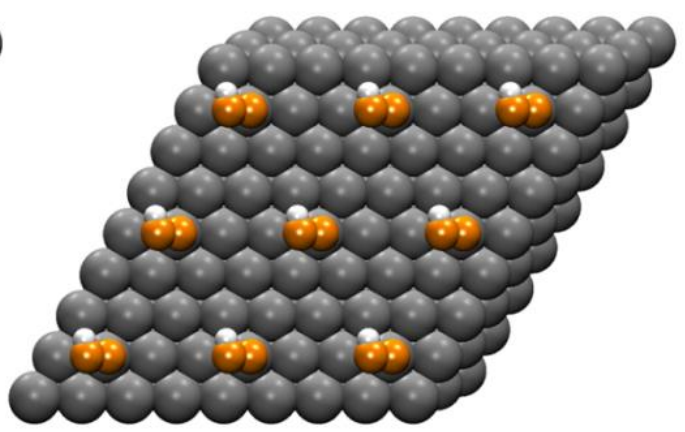

$\Delta G^{\mathrm{vac}}=4.22 \mathrm{eV}$

b) water bilayer (WB)

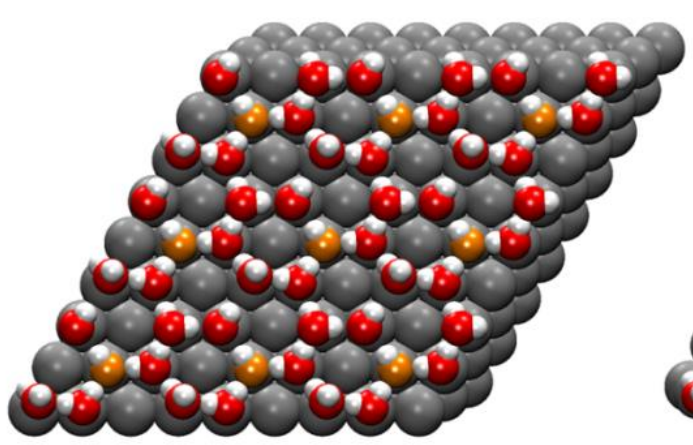

$\Delta G_{O H}^{\text {UB }}=0.55 \mathrm{eV}$

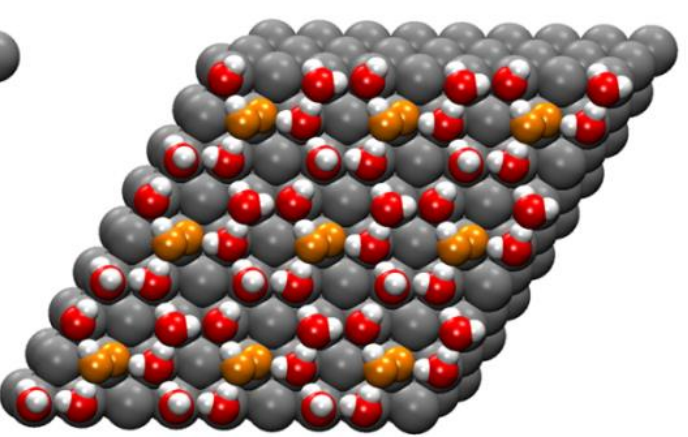

$\Delta G^{\mathrm{WOH}}=3.83 \mathrm{eV}$

c) micro-solvation (MS)

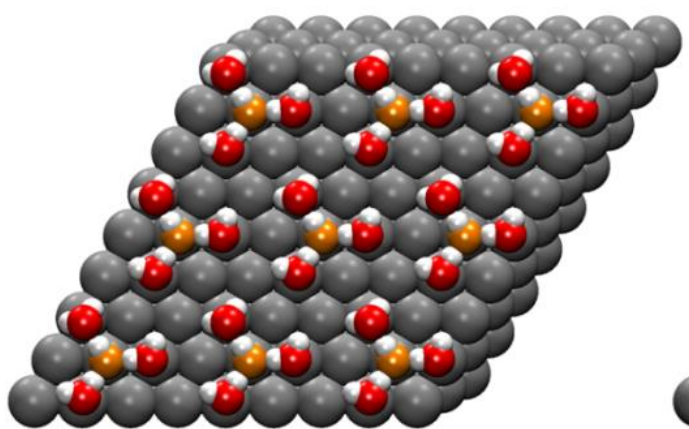

$\Delta G_{O H}^{M S}=0.51 \mathrm{eV}$

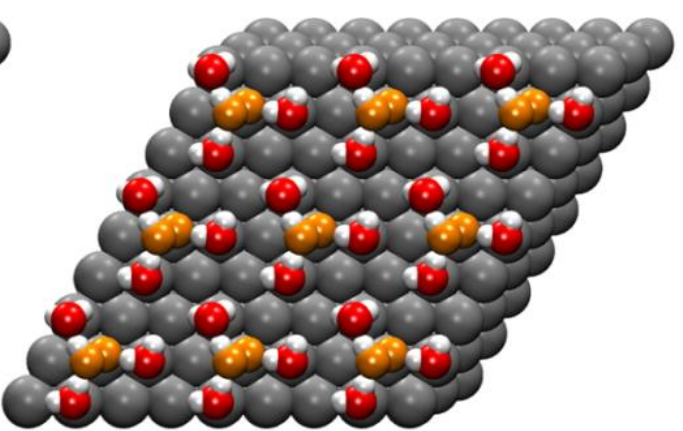

$\Delta G_{O O H}^{M S}=3.85 \mathrm{eV}$

Figure 1. $\Delta G_{O H}$ (left) and $\Delta G_{O O H}$ (right) at $\mathrm{pH}=0$ and $298.15 \mathrm{~K}$ on $\mathrm{Pt}(111)$ in a) vacuum; b) a periodic water bilayer; c) a micro-solvation environment with three coadsorbed water molecules. $\mathrm{O}$ atoms in $* \mathrm{OH} / * \mathrm{OOH}$ appear in orange.

We define the solvation energy (or solvation correction) of adsorbate $A\left(\Omega_{A}\right)$ as the difference between the adsorption energies in vacuum and within the bilayer (Figure 1a-b): 
$\Omega_{A}=\Delta G_{A}^{W B}-\Delta G_{A}^{v a c}$. Within the water bilayer, $\Omega_{O H}=-0.63 \mathrm{eV}$ and $\Omega_{O O H}=-0.39 \mathrm{eV}$, in line with previous results. ${ }^{19,23-26,31}$ These energies calculated with an implicit method (VASPsol ${ }^{32}$ ) are severely underestimated $\left(-0.16 /-0.22 \mathrm{eV}\right.$, see also $\left.{ }^{14,33}\right)$, as hydrogen-bound solvation effects on adsorbates are usually not captured by a dielectric constant and a radius, because hydrogen bonds are: (1) directional (some species donate and some others receive depending on their composition and chemical structure), (2) localized (it is not an interaction of the solvent as a whole over the adsorbate but rather of certain particular parts of such solvent near the adsorbate), and (3) short ranged (it fades as the adsorbate-solvent distance increases). Previous works showed that the problems can be corrected by adding an explicit first solvation shell. ${ }^{13}$ Importantly, Figure $1 \mathrm{c}$ shows that it is not necessary to generate water bilayers covering the entire surface or combine implicit and explicit methods to account for solvation, as the differences in $\Delta G_{O H}$ and $\Delta G_{O O H}$ between water bilayers and micro-solvation are 0.04 and $0.02 \mathrm{eV}$. We also calculated the difference between the ${ }^{*} \mathrm{OH}$ and ${ }^{*} \mathrm{OOH}$ solvation energies in an explicit bilayer with and without implicit water using VASPsol ${ }^{32}$ to be only 2 and $13 \mathrm{meV}$. Solvation energies with and without dispersion in the calculations are also nearly identical, see section S6. Thus, only three water molecules per $* \mathrm{OH} /{ }^{*} \mathrm{OOH}$ suffice to account for the leading chemistry: two creating $\mathrm{H}$-bonds with $\mathrm{O}$ atoms in the adsorbates and another creating $\mathrm{H}$-bonds with their $\mathrm{H}$ atoms. The up or down orientations of water molecules in the bilayers or micro-solvation environments do not affect our results, as those orientations are typically retained in the calculations of the half-dissociated layers (see Fig. $\mathrm{S} 4 \mathrm{~g})$.

Optimized nanoparticles from Wulff constructions ${ }^{29}$ in the range $0.9-2.7 \mathrm{~nm}$ are provided in Figure 2a-d. Figure 2e shows that the micro-solvation approach does not significantly differ from one with a larger water coverage (denoted "extended" including an in-plane second solvation shell around $* \mathrm{OH})$ by just $0.05 \mathrm{eV}$ on $\mathrm{Pt}_{201}$. As shown below, this is 
within the confidence interval of the method and provides the accuracy required in e.g. ORR electrocatalysis. ${ }^{26,31}$ Thus, we conclude that $\Omega_{A}=\Delta G_{A}^{W B}-\Delta G_{A}^{v a c} \approx \Delta G_{A}^{M S}-\Delta G_{A}^{v a c}$.

Next, we use this simple yet relatively accurate micro-solvation approximation to evaluate $\Omega_{O H}$ and $\Omega_{O O H}$ on various atop sites of model nanoparticles, ${ }^{29}$ specifically $\mathrm{Pt}_{38}, \mathrm{Pt}_{79}$, $\mathrm{Pt}_{201}$ and $\mathrm{Pt}_{586}$ (Figure $2 \mathrm{a}-\mathrm{d}$ ) as a function of generalized coordination numbers $(\overline{C N}):^{3-4,34-35}$

$$
\overline{C N}(i)=\sum_{j=1}^{n_{i}} \frac{c n(j)}{c n_{\max }}
$$

The generalized coordination number of an atom $i(\overline{C N}(i))$ is the weighted average of the conventional coordination numbers $(\operatorname{cn}(j))$ of the $n_{\text {i }}$ nearest neighbors. The normalization factor $\left(c n_{\max }\right)$ for atop sites is the bulk coordination (12 for fcc metals). $\overline{C N}$ captures strain, ${ }^{35}$ finite-size and multisite effects, ${ }^{3-4,34}$ permitting direct comparison among a variety of metal nanoparticles and extended surfaces, which is habitually challenging. ${ }^{29}$ 


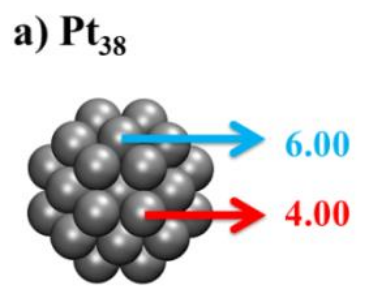

c) $\mathrm{Pt}_{201}$


d) $\mathrm{Pt}_{586}$

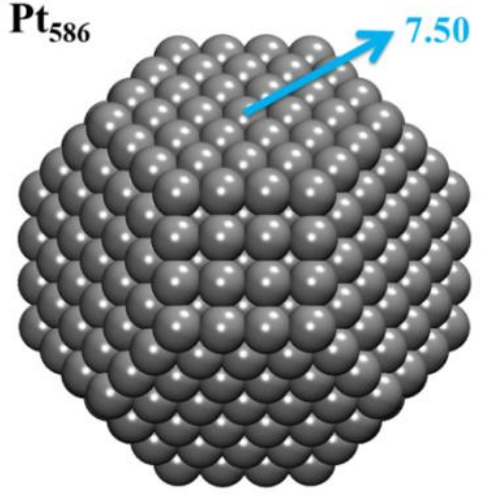

e) "extended" vs micro solvation for $\overline{\mathrm{CN}}=7.5$ on $\mathrm{Pt}_{201}$
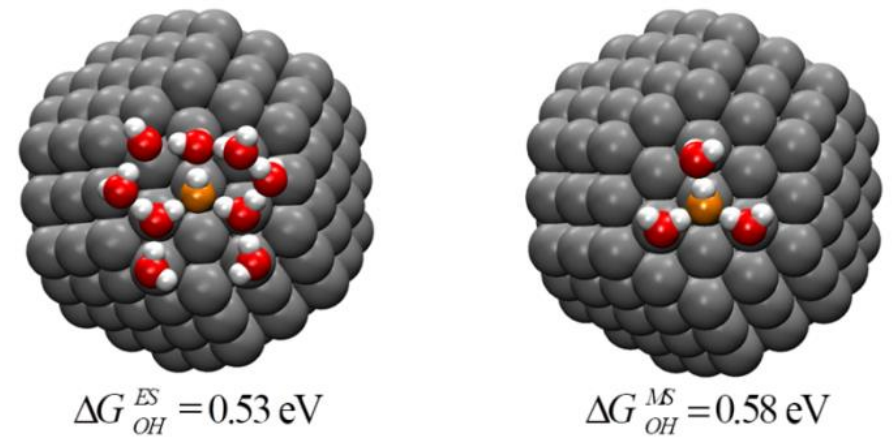

Figure 2. $\overline{C N}$ for non-equivalent atop sites on: a) $\mathrm{Pt}_{38}$, b) $\mathrm{Pt}_{79}$, c) $\mathrm{Pt}_{201}$, d) $\mathrm{Pt}_{586} . \overline{C N}$ is provided for sites with $c n=9$ (blue), 8 (green), 7 (orange) and 6 (red). e) Comparison between "extended" $\left({ }^{*} \mathrm{OH}+9 * \mathrm{H}_{2} \mathrm{O}\right)$ and micro-solvation $\left(* \mathrm{OH}+3 * \mathrm{H}_{2} \mathrm{O}\right.$ ) approaches on $\mathrm{Pt}_{201}$.

Figure 3 contains $\Delta G_{O H}$ and $\Delta G_{O O H}$ in vacuum and micro-solvated as a function of $\overline{C N}$. Note that section $\mathrm{S} 4$ shows that $\overline{C N}$ describes the trends ostensibly better than $\mathrm{cn}$. The data in Figure 3 appear in Table S1 and the configurations in Figures S2-S4. The trends for $\Delta G_{O H}$ and $\Delta G_{O о н}$ with and without solvation are linear and approximately parallel, allowing to obtain average solvation corrections for each adsorbate, regardless of the surface sites and particle size (up to $\mathrm{Pt}_{38}$, a sub-nanometer particle). The corrections are $\Omega_{O H}^{a v g}=-0.59 \mathrm{eV}$ and 
$\Omega_{\text {ooH }}^{\text {avg }}=-0.47 \mathrm{eV}$ with standard deviations in both cases of $0.10 \mathrm{eV}$, in agreement with bilayer solvation models for (111) surfaces (see Figure 1 and refs. ${ }^{19,} 23-26,31$ ). Intervals of \pm 0.14 and $\pm 0.13 \mathrm{eV}$, smaller than the intrinsic error of DFT-GGAs, ${ }^{36}$ guarantee confidence of $85 \%$. Hence, one can safely add these solvation energies to $\Delta G_{A}$ calculated in vacuum to rapidly include solvation effects on Pt nanoparticles $\left(\Delta G_{A}^{W B} \approx \Delta G_{A}^{M S}=\Delta G_{A}^{v a c}+\Omega_{A}\right)$.

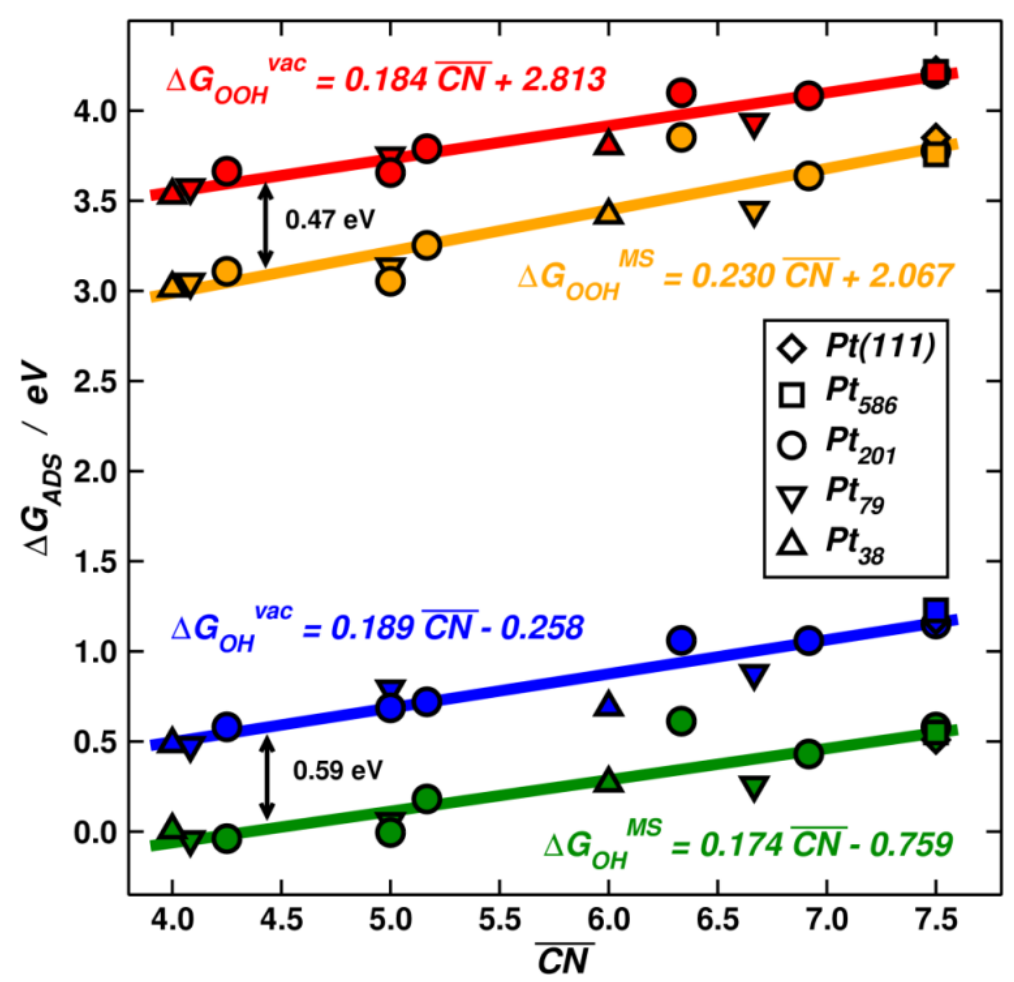

Figure 3. $\Delta \mathrm{G}_{\mathrm{OH}}$ and $\Delta \mathrm{G}_{\mathrm{OOH}}$ in vacuum (blue/red) and micro-solvated (green/orange) on nanoparticles and $\operatorname{Pt}(111)$ as a function of $\overline{C N}$ (see Figure 2). The vertical differences between the points provide $\Omega_{O H}^{a v g}=-0.59 \pm 0.14 \mathrm{eV}$ and $\Omega_{O O H}^{\text {avg }}=-0.47 \pm 0.13 \mathrm{eV}$, see further details on sections S1 and S4.

In case not only shifts to the energies in vacuum are needed and explicit solvent descriptions are required, micro-solvation is also helpful: for instance, $\mathrm{Pt}_{201}$ has a diameter of $\sim 1.7 \mathrm{~nm}$ and AIMD simulations at $350 \mathrm{~K}$ found that $\sim 1 / 3$ of the 122 surface atoms are covered by water. ${ }^{11}$ Thus, the high computational cost required to dynamically describe water/metal interfaces at finite temperature makes our static approach useful, as merely three water molecules and no implicit environment are needed. 
$* \mathrm{OH}$ is typically more stabilized by solvation than $* \mathrm{OOH}^{4,19,26,31}$ because $\mathrm{O}-\mathrm{H}$ bonds in the latter are less polarized due to the O-O bond (exemplified in Figure S1 by means of electronic charges on the adsorbates), making H-bonds slightly weaker. We anticipate that the micro-solvation approach could be applied to other important adsorbates in electrocatalysis such as $* \mathrm{NH}_{\mathrm{x}},{ }^{*} \mathrm{NOH}, * \mathrm{NHOH},{ }^{*} \mathrm{COH},{ }^{*} \mathrm{CHOH}$ and $* \mathrm{CH}_{2} \mathrm{OH}$, among others, ensuring that a) all moieties able to create $\mathrm{H}$-bonds are close to surrounding water molecules, and b) analyzing the water-water vs water-adsorbate stabilizations. Other metals and alloys could also be tested, ${ }^{13,31}$ so that adsorbate- and metal-dependent corrections are obtained for nanoparticles. Furthermore, the adsorbate's coverage, the number and orientation of surrounding waters and spectators (e.g. *O during ORR) impact adsorbate solvation, so that our corrections can be used as an upper bound, ${ }^{24,26,28}$ in addition, coadsorbed ions can as well modify solvation contributions to the adsorption energies. ${ }^{37}$

The largest deviations from the fits for solvated $* \mathrm{OH} / * \mathrm{OOH}$ (green/orange) in Figure 3 correspond to $\overline{C N}=6.33$, at (100) terraces in $\mathrm{Pt}_{201}$ (Figure 2). This suggests that solvation on square-like facets might be weaker than on hexagonal facets, which is supported by $\Omega_{O H}=-0.39 \mathrm{eV}$ on $\mathrm{Pt}(100)$, calculated with the micro-solvation approach. We attribute this to the different surface symmetries (Pt-Pt-Pt angles of $90^{\circ}$ vs $120^{\circ}$ ), which impact water coadsorption and H-bonding. Excluding those data from the fits does not ostensibly affect the average solvation corrections $\left(\Omega_{O H}^{a v g}=-0.60 \pm 0.14 \mathrm{eV}\right.$ and $\Omega_{O O H}^{a v g}=-0.49 \pm 0.12 \mathrm{eV}$ ), but the standard deviations decrease to $0.09 / 0.08 \mathrm{eV}$ and the confidence of the intervals reaches $92 \%$.

Summarizing, we provide here an affordable micro-solvation approach to account for water solvation of oxygenates with accuracy comparable to bilayers with/without implicit media. The approach has two advantages: 1) only 3 water molecules are needed, with no need for an implicit solvent or dispersion corrections. 2) Average solvation corrections are rapidly 
obtained for nanoparticles, estimated as $\Omega_{O H}^{a v g}=-0.59 \pm 0.14 \mathrm{eV}$ and $\Omega_{O O H}^{a v g}=-0.47 \pm 0.13 \mathrm{eV}$ on Pt.

\section{COMPUTATIONAL METHODS}

We carried out the calculations with VASP. ${ }^{38}$ See full details in the SI, section S5.

\section{Notes}

We declare no competing financial interests.

\section{ACKNOWLEDGMENT}

We thank NCF, IDRIS, CINES (project 609, GENCI/CT8) and PSMN for CPU time and assistance. F.C.-V. thanks MICIU for a Ramón y Cajal research contract (RYC-2015-18996). FI's research is supported by MINECO/FEDER CTQ2015-64618-R and Generalitat de Catalunya 2017SGR13 grants, and the 2015 ICREA Academia Award for Excellence in University Research. F.C.-V. and F.I. acknowledge financial support from MICIU through the program “Units of Excellence María de Maeztu” (grant MDM-2017-0767).

Supporting Information available: Data in Figures 1-3, micro-solvation configurations on nanoparticles (figures and xyz coordinates), comparison between coordination numbers, computational details and calculations including dispersion corrections. This material is available free of charge via the Internet at http://pubs.acs.org

\section{REFERENCES}

1. Hammer, B.; Nørskov, J. K. Theoretical surface science and catalysis-calculations and concepts. In Adv. Catal., Bruce C. Gates, H. K., Ed. Academic Press: 2000; Vol. Volume 45, pp 71-129. 
2. Climent, V.; Feliu, J. Thirty years of platinum single crystal electrochemistry. J. Solid State Electrochem. 2011, 15 (7-8), 1297-1315.

3. Calle-Vallejo, F.; Martínez, J. I.; García-Lastra, J. M.; Sautet, P.; Loffreda, D. Fast Prediction of Adsorption Properties for Platinum Nanocatalysts with Generalized Coordination Numbers. Angew. Chem. Int. Ed. 2014, 53 (32), 8316-8319.

4. $\quad$ Calle-Vallejo, F.; Tymoczko, J.; Colic, V.; Vu, Q. H.; Pohl, M. D.; Morgenstern, K.; Loffreda, D.; Sautet, P.; Schuhmann, W.; Bandarenka, A. S. Finding optimal surface sites on heterogeneous catalysts by counting nearest neighbors. Science 2015, 350 (6257), 185-189.

5. Su, H.-Y.; Sun, K.; Wang, W.-Q.; Zeng, Z.; Calle-Vallejo*, F.; Li, W.-X. Establishing and Understanding Adsorption-Energy Scaling Relations with Negative Slopes. The Journal of Physical Chemistry Letters 2016, 7 (24), 5302-5306.

6. Calle-Vallejo, F.; Krabbe, A.; Garcia-Lastra, J. M. How covalence breaks adsorption-energy scaling relations and solvation restores them. Chemical Science 2017, 8 (1), 124-130.

7. Karlberg, G. S.; Rossmeisl, J.; Norskov, J. K. Estimations of electric field effects on the oxygen reduction reaction based on the density functional theory. Phys. Chem. Chem. Phys. 2007, 9 (37), 5158-5161.

8. Rossmeisl, J.; Chan, K.; Ahmed, R.; Tripkovic, V.; Bjorketun, M. E. pH in atomic scale simulations of electrochemical interfaces. Phys. Chem. Chem. Phys. 2013, 15 (25), 10321-10325.

9. Sakong, S.; Naderian, M.; Mathew, K.; Hennig, R. G.; Groß, A. Density functional theory study of the electrochemical interface between a Pt electrode and an aqueous electrolyte using an implicit solvent method. J. Chem. Phys. 2015, 142 (23), 234107.

10. Sakong, S.; Groß, A. The Importance of the Electrochemical Environment in the ElectroOxidation of Methanol on Pt(111). ACS Catalysis 2016, 6 (8), 5575-5586.

11. de Morais, R. F.; Kerber, T.; Calle-Vallejo, F.; Sautet, P.; Loffreda, D. Capturing Solvation Effects at a Liquid/Nanoparticle Interface by Ab Initio Molecular Dynamics: Pt201 Immersed in Water. Small 2016, 12 (38), 5312-5319.

12. Cramer, C. J.; Truhlar, D. G. Implicit Solvation Models: Equilibria, Structure, Spectra, and Dynamics. Chem. Rev. 1999, 99 (8), 2161-2200.

13. Garcia-Ratés, M.; García-Muelas, R.; López, N. Solvation Effects on Methanol Decomposition on $\mathrm{Pd}(111), \mathrm{Pt}(111)$, and Ru(0001). The Journal of Physical Chemistry C 2017, 121 (25), 13803-13809.

14. Zhang, Q.; Asthagiri, A. Solvation effects on DFT predictions of ORR activity on metal surfaces. Catalysis Today 2019, 323, 35-43.

15. Rempe, S. B.; Pratt, L. R. The hydration number of $\mathrm{Na}+$ in liquid water. Fluid Phase Equilibria 2001, 183-184, 121-132.

16. Sicinska, D.; Paneth, P.; Truhlar, D. G. How Well Does Microsolvation Represent Macrosolvation? A Test Case: Dynamics of Decarboxylation of 4-Pyridylacetic Acid Zwitterion. The Journal of Physical Chemistry B 2002, 106 (10), 2708-2713.

17. Bryantsev, V. S.; Diallo, M. S.; Goddard Iii, W. A. Calculation of Solvation Free Energies of Charged Solutes Using Mixed Cluster/Continuum Models. The Journal of Physical Chemistry B 2008, 112 (32), 9709-9719.

18. Carrasco, J.; Hodgson, A.; Michaelides, A. A molecular perspective of water at metal interfaces. Nat. Mater. 2012, 11 (8), 667-674.

19. Tripković, V.; Skúlason, E.; Siahrostami, S.; Nørskov, J. K.; Rossmeisl, J. The oxygen reduction reaction mechanism on $\mathrm{Pt}(111)$ from density functional theory calculations. Electrochim. Acta 2010, 55 (27), 7975-7981.

20. Schnur, S.; Groß, A. Properties of metal-water interfaces studied from first principles. New J. Phys. 2009, 11 (12), 125003.

21. Kolb, M. J.; Wermink, J.; Calle-Vallejo, F.; Juurlink, L. B. F.; Koper, M. T. M. Initial stages of water solvation of stepped platinum surfaces. Phys. Chem. Chem. Phys. 2016, 18 (5), 3416-3422.

22. Kolb, M. J.; Farber, R. G.; Derouin, J.; Badan, C.; Calle-Vallejo, F.; Juurlink, L. B. F.; Killelea, D. R.; Koper, M. T. M. Double-Stranded Water on Stepped Platinum Surfaces. Phys. Rev. Lett. 2016, 116 (13), 136101. 
23. Nørskov, J. K.; Rossmeisl, J.; Logadottir, A.; Lindqvist, L.; Kitchin, J. R.; Bligaard, T.; Jónsson, H. Origin of the Overpotential for Oxygen Reduction at a Fuel-Cell Cathode. J. Phys. Chem. B 2004, 108 (46), 17886-17892.

24. Casalongue, H. S.; Kaya, S.; Viswanathan, V.; Miller, D. J.; Friebel, D.; Hansen, H. A.; Nørskov, J. K.; Nilsson, A.; Ogasawara, H. Direct observation of the oxygenated species during oxygen reduction on a platinum fuel cell cathode. Nat. Commun. 2013, 4, article number 2817.

25. Greeley, J.; Stephens, I. E. L.; Bondarenko, A. S.; Johansson, T. P.; Hansen, H. A.; Jaramillo, T. F.; Rossmeisl, J.; Chorkendorff, I.; Nørskov, J. K. Alloys of platinum and early transition metals as oxygen reduction electrocatalysts. Nat. Chem. 2009, 1 (7), 552-556.

26. He, Z.-D.; Hanselman, S.; Chen, Y.-X.; Koper, M. T. M.; Calle-Vallejo, F. Importance of Solvation for the Accurate Prediction of Oxygen Reduction Activities of Pt-Based Electrocatalysts. The Journal of Physical Chemistry Letters 2017, 8 (10), 2243-2246.

27. Perez-Alonso, F. J.; McCarthy, D. N.; Nierhoff, A.; Hernandez-Fernandez, P.; Strebel, C.; Stephens, I. E. L.; Nielsen, J. H.; Chorkendorff, I. The Effect of Size on the Oxygen Electroreduction Activity of Mass-Selected Platinum Nanoparticles. Angew. Chem. Int. Ed. 2012, 51 (19), 4641-4643.

28. Calle-Vallejo, F.; Pohl, M. D.; Reinisch, D.; Loffreda, D.; Sautet, P.; Bandarenka, A. S. Why conclusions from platinum model surfaces do not necessarily lead to enhanced nanoparticle catalysts for the oxygen reduction reaction. Chemical Science 2017, 8 (3), 2283-2289.

29. Vines, F.; Gomes, J. R. B.; Illas, F. Understanding the reactivity of metallic nanoparticles: beyond the extended surface model for catalysis. Chemical Society Reviews 2014, 43 (14), 4922-4939. 30. Feibelman, P. J. Partial Dissociation of Water on Ru(0001). Science 2002, 295 (5552), 99.

31. Tripkovic, V. Thermodynamic assessment of the oxygen reduction activity in aqueous solutions. Physical Chemistry Chemical Physics 2017, 19 (43), 29381-29388.

32. Mathew, K.; Sundararaman, R.; Letchworth-Weaver, K.; Arias, T. A.; Hennig, R. G. Implicit solvation model for density-functional study of nanocrystal surfaces and reaction pathways. The Journal of Chemical Physics 2014, 140 (8), 084106.

33. Saravanan, K.; Wang, G.; Keith, J. A. Quantifying solvation energies at solid/liquid interfaces using continuum solvation methods AU - Gray, Corinne M. Molecular Simulation 2017, 43 (5-6), 420427.

34. Calle-Vallejo, F.; Sautet, P.; Loffreda, D. Understanding Adsorption-Induced Effects on Platinum Nanoparticles: An Energy-Decomposition Analysis. J. Phys. Chem. Lett. 2014, 5 (18), 31203124.

35. Calle-Vallejo, F.; Bandarenka Aliaksandr, S. Enabling Generalized Coordination Numbers to Describe Strain Effects. ChemSusChem 2018, 11 (11), 1824-1828.

36. Kurth, S.; Perdew, J. P.; Blaha, P. Molecular and solid-state tests of density functional approximations: LSD, GGAs, and meta-GGAs. Int. J. Quantum Chem. 1999, 75 (4-5), 889-909.

37. Chen, X.; McCrum, I. T.; Schwarz, K. A.; Janik, M. J.; Koper, M. T. M. Co-adsorption of Cations as the Cause of the Apparent $\mathrm{pH}$ Dependence of Hydrogen Adsorption on a Stepped Platinum SingleCrystal Electrode. Angewandte Chemie International Edition 2017, 56 (47), 15025-15029.

38. Kresse, G.; Furthmüller, J. Efficient iterative schemes for ab initio total-energy calculations using a plane-wave basis set. Phys. Rev. B 1996, 54 (16), 11169-11186. 